\title{
BMJ Open Comparative efficacy and safety of alternative glucocorticoids regimens in patients with ANCA-associated vasculitis: a systematic review
}

\author{
Yingqi Xiao (D) , , ${ }^{1,2}$ Gordon Guyatt, ${ }^{1,3}$ Linan Zeng (D) ,,4 David RW Jayne, ${ }^{5}$ \\ Peter A Merkel, ${ }^{6}$ Reed AC Siemieniuk (D) , ${ }^{1,3}$ Jared E Dookie, ${ }^{7}$ Tayler A Buchan, ${ }^{1}$ \\ Muhammad Muneeb Ahmed (i) , ${ }^{8}$ Rachel J Couban, ${ }^{9}$ Alfred Mahr, ${ }^{10}$ \\ Michael Walsh (1) 1,3,11
}

To cite: Xiao Y, Guyatt G, Zeng $L$, et al. Comparative efficacy and safety of alternative glucocorticoids regimens in patients with ANCA-associated vasculitis: a systematic review. BMJ Open 2022;12:e050507. doi:10.1136/ bmjopen-2021-050507

- Prepublication history and additional supplemental material for this paper are available online. To view these files, please visit the journal online (http://dx.doi.org/10.1136/ bmjopen-2021-050507).

Received 23 February 2021 Accepted 09 December 2021

Check for updates

(C) Author(s) (or their employer(s)) 2022. Re-use permitted under CC BY-NC. No commercial re-use. See rights and permissions. Published by BMJ.

For numbered affiliations see end of article.

Correspondence to

Dr Yingqi Xiao;

xiaoyingqixyq@163.com

\section{ABSTRACT}

Objective To compare the efficacy and safety of alternative glucocorticoids (GCs) regimens as induction therapy for patients with antineutrophil cytoplasmic antibodies (ANCA)-associated vasculitis.

Design Systematic review of randomised controlled trials (RCTs).

Data sources Medline, Embase, Clinicaltrials.gov and Cochrane Central Register of Controlled Trials up to 10 April 2020.

Study selection and review methods RCTs comparing two (or more) different dose regimens of GC in ANCAassociated vasculitis during induction of remission, regardless of other therapies. Pairs of reviewers independently screened records, extracted data and assessed risk of bias. Two reviewers rated certainty of evidence using the Grading of Recommendations Assessment, Development, and Evaluation approach. Results 0 f 3912 records identified, the full texts of two records met the eligibility criteria. Due to the heterogeneity of population and dose regimen of GCs between the two trials, we descriptively presented the two trials and did not combine the results using meta-analysis. Compared with the standard-dose regimen, the reduced-dose regimen of $\mathrm{GC}$ may reduce death risk difference (RD): from $-1.7 \%$ to $-2.1 \%$, low certainty), while not increasing end-stage kidney disease (ESKD) (RD: from $-1.5 \%$ to $0.4 \%$, moderate certainty). The reduced-dose regimen probably has an important reduction in serious infections at 1 year (RD: from $-12.8 \%$ to $-5.9 \%$, moderate certainty). Reduceddose regimen of GCs probably has trivial or no effect in disease remission, relapse or health-related quality of life (moderate to high certainty).

Conclusions The reduced-dose regimen of GC may reduce death at the follow-up of 6 months to longer than 1 year and serious infections while not increasing ESKD. PROSPERO registration number CRD42020179087.

\section{INTRODUCTION}

Antineutrophil cytoplasmic antibodies (ANCA)-associated vasculitis (AAV) comprises a subgroup of systemic vasculitis

\section{Strengths and limitations of this study}

- This systematic review included a comprehensive search of literatures without limitation on language.

- This systematic review applied Grading of Recommendations Assessment, Development, and Evaluation approach assessing the quality of evidence.

- This systematic review included the largest global trial and the latest trial on the subject so far that have improved the generalisability of the results through the efforts of national and international vasculitis networks and extensive selection criteria.

- Despite the excellent methodological quality, the two eligible trials were open labelled and were subject to bias.

- This systematic review is mainly based on evidence from patients with severe antineutrophil cytoplasmic antibodies-associated vasculitis is uncertain.

affecting small-sized to medium-sized vessels, a chronic inflammatory disease of the blood vessel wall, ${ }^{1}$ and includes granulomatosis with polyangiitis (GPA), microscopic polyangiitis (MPA) and eosinophilic granulomatosis with polyangiitis (EGPA). ${ }^{2}$ Patients with AAV usually test positive for ANCA. The cause of the disease remains unclear. Genetic and environmental factors play an important role in the onset of the disease. ${ }^{34}$ The annual incidence of AAV is about 20 per million inhabitants, and the prevalence is about 100 per million inhabitants. ${ }^{5} \mathrm{AAV}$ has multiple clinical manifestations, characterised by leucocytes infiltrating the vessel walls, fibrinoid necrosis and vascular damage with occlusion or aneurysm formation. ${ }^{6}$ The severity of AAV varies greatly, but after months to years of non-severe manifestations, patients with non-severe diseases often progress to severe 
diseases. ${ }^{7}$ The most common severe AAV manifestation is glomerulonephritis, which leads to renal failure and alveolar capillaritis causing pulmonary haemorrhage. ${ }^{8}$ Previous studies have shown that untreated AAV is typically fatal, ${ }^{9}$ with 6 -month and 1-year mortality rates of $60 \%$ and $80 \%$, respectively. ${ }^{10}$

Since the 1950s, glucocorticoids (GCs), as immunosuppressants and anti-inflammatory drugs with a fast-acting and powerful anti-inflammatory effect, became the basis of therapy for AAV. ${ }^{112}$ The main mechanism of action is genomic and non-genomic effects mediated by cytosolic GC receptors or specific and non-specific interactions with membrane-bound GC receptors resulting in reduced production of proinflammatory proteins (transrepression). ${ }^{13}$ However, monotherapy has incomplete efficacy. ${ }^{14}$ Subsequently, standard therapy emerged using the combination of high-dose GC and cyclophosphamide to achieve remission in AAV. ${ }^{15-17}$ This combination therapy proved to reduce mortality to $25 \%$ at 5 years and has high remission rates of $80 \%-90 \% .{ }^{18}$ In addition to cyclophosphamide, clinical remission can also be achieved with rituximab-based or methotrexate-based therapies. ${ }^{19}$ Although the combination of high-dose GC and cytotoxic drugs greatly enhances the therapeutic efficacy, high-dose GC may increase the toxicity associated with treatment. Infections and cardiovascular diseases due to the treatment are main causes of fatal side effects that reduced quality of life (QOL) in patients. ${ }^{20}{ }^{21}$ Previous studies have shown that lower GC doses during the induction period were associated with higher relapse rates and longer term of GC use that might expose patients to the potential toxicity of high-cumulative GC. ${ }^{22} 23$

The purpose of this systematic review is to evaluate the comparative efficacy and safety of alternative GC regimens (two or more different doses of GC) in patients with ANCA-associated vasculitis. Our systematic review is part of a BMJ Rapid Recommendations project, which is based on the shared vision of the MAGIC Evidence Ecosystem Foundation (www.magicproject.org) and The BMJ. When there is evidence that may change the clinical practice, the cooperative organisations will act quickly to provide a timely, trustworthy practice guideline. Under such circumstance, the exciting evidence was the PEXIVAS trial. ${ }^{24}$ The systematic review informed an associated BMJ Rapid Recommendations.

\section{METHODS}

\section{Registration and report}

A priori protocol of this systematic review is presented at PROSPERO (CRD42020179087). We reported this systematic review and meta-analysis based on the Preferred Reporting Items for Systematic Reviews and Meta-Analyses (PRISMA) statement (see online supplemental appendix 1). ${ }^{25}$

\section{Patient and public involvement}

According to the process of the BMJ Rapid Recommendations, the guideline panel on this target provides critical process oversight and content guidance for the systematic review. The guideline panel consisted of clinicians, methodologists, pharmacists, patient partners with AAV and caregiver partner. Patients received relevant training and support to meet patient involvement content throughout the guideline development process, including critical feedback on outcome and subgroup selection, Grading of Recommendations Assessment, Development, and Evaluation (GRADE) judgments and manuscript feedback.

\section{Study selection}

We included studies of patients with a diagnosis of active AAV. AAV is defined as the following categories according to the Chapel Hill Consensus Conference 2012 classification method: MPA, GPA and EGPA (Churg-Strauss syndrome).${ }^{26}$ In addition, single organ damage AAV (eg, renal limited vasculitis or idiopathic rapidly progressive glomerulonephritis) can be considered the fourth entity, although in practice it eventually corresponds to the kidney-limited form of MPA or GPA. ${ }^{27}$

Eligible studies are defined as comparing two or more doses of GC in patients with AAV during induction of remission, regardless of the use of other therapies. Other therapies include, but are not limited to cyclophosphamide, azathioprine, rituximab, methotrexate, mycophenolate mofetil and plasma exchange. We included only randomised controlled trial (RCTs). Outcomes of interest included death, end-stage kidney disease (ESKD), serious infections, serious adverse events other than serious infection, sustained remission and any other patient-important outcomes. The time point for the outcome assessment depends on what was specified in individual studies.

\section{Data sources and searches}

A professional medical librarian developed a literature search strategy and searched Medline, Embase, Clinicaltrials.gov and Cochrane Central Register of Controlled Trials (CENTRAL) for relevant studies from the inception to 10 April 2020 with no restriction on language. Online supplemental appendix 2 presents the literature search strategies and results. We also reviewed the reference lists of included studies for additional references. Pairs of reviewers (YX, JED, TAB, MMA) independently screened titles and abstracts, and reviewed the full texts of potentially eligible studies to determine the final eligible studies. Disagreements were resolved by discussion. To ensure the validity and consistency of the process, we provided reviewers with review instruction and conducted calibration exercises before the formal start of each process.

\section{Data extraction and risk of bias assessment}

We collected data through a predesigned excel extraction form. Pairs of reviewers (YX, JED, TAB, MMA) extracted data independently. We resolved disagreements by discussion. For each eligible study, we collected the following: country/region, design of the study, patient characteristics (mean age, sex and disease diagnosis), treatment 
strategy, outcomes and measures and follow-up duration. Pair of reviewers (YX, JED, TAB, MMA) independently assessed the risk of bias of each RCT using a revised Cochrane risk of bias tool that includes sequence generation, concealment of allocation, blinding (participants, personnel and outcome assessors), loss to follow-up, selective outcome reporting and other potential sources of bias. ${ }^{28}$ The reviewers judged each criterion as definitely or probably low risk of bias, or probably or definitely high risk of bias.

\section{Data synthesis or analysis, and grading of evidence}

If data permitted, we planned to conduct meta-analysis for each of the outcomes. For continuous outcomes, we planned to use inverse variance statistical method to calculate mean difference and 95\% CI. For binary outcomes, we would use the Mantel-Haenszel statistical method to calculate risk ratio and $95 \%$ CI. We planned to conservatively use a priori random effects model assuming a great variability in treatment effects across the study. We planned to use the $I^{2}$ statistic to assess statistical heterogeneity. And when the effect-estimated $I^{2}$ value is $>30 \%$, we would attempt to determine the reason for the heterogeneity. Subgroups would depend on the outcomes of the included studies report. We planned to check the funnel plot for potential publication bias if the number of eligible studies in the analysis exceeded ten. We set significance at $\mathrm{p}=0.05$ and would use RevMan .5 .3 for all statistical analyses.

We used the GRADE approach ${ }^{29}$ to assess the quality of evidence at outcome level by two reviewers (LZ and YX). We focused on the grading of the following outcomes after our team discussion: death, ESKD, serious infections at 1 year, serious adverse events and health-related QoL. Disagreements were resolved by discussion or through a third reviewer (GG) adjudication. RCTs started as high quality. We summarised the quality of evidence in GRADE summary of findings using the MAGICapp platform. ${ }^{30} 31$

\section{RESULTS}

\section{Literature search}

The search yielded, after removal of duplicates, 3912 records, 38 of which were considered for full-text review. The PRISMA flow chart (figure 1), presents the reasons for excluding studies at the stage of full-text screening. Ultimately, two RCTs met the inclusion criteria. ${ }^{18} 24$ The full text of one of the two RCTs ${ }^{18}$ was published after our initial submission of this systematic review. We updated our results after the full text was published.

\section{Included studies}

The RCT by Walsh et a $l^{24}$ was a multicentre trial including 704 patients with severe AAV at 95 centres in 16 countries (median duration of follow-up: 2.9 years). This study was a 2-by-2 factorial design and compared the efficacy of plasma exchange with or without plasma exchange for $\mathrm{AAV}$, as well as the efficacy of a reduced-dose regimen and

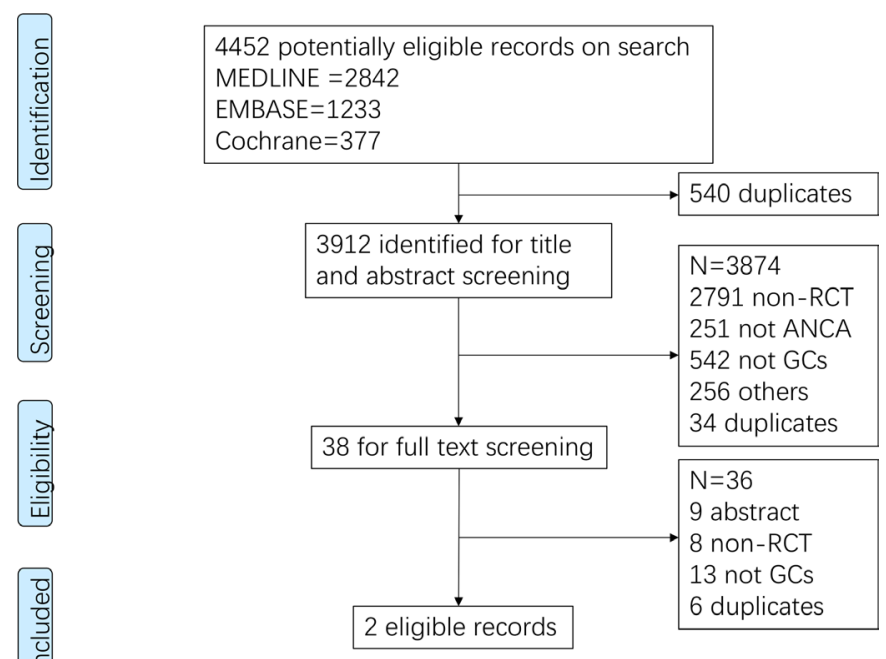

Figure 1 Preferred Reporting Items for Systematic Reviews and Meta-Analyses flow chart of literature search and screening process. ANCA, antineutrophil cytoplasmic antibodies; GCs, glucocorticiods; RCT, randomised controlled trial.

a standard-dose regimen of GC over the first 6 months of the treatment period. The two regimens of oral GC, specifically, patients in the reduced-dose regimen and standard-dose regimen received the same treatment in the first week - the dose was determined according to the patients' weight $(50.0 \mathrm{mg} /<50 \mathrm{~kg}, 60.0 \mathrm{mg} / 50-75 \mathrm{~kg}$, $75.0 \mathrm{mg} />75 \mathrm{~kg}$ ). The reduced-dose regimen and the standard-dose regimen began to decrease gradually in the second and third weeks, respectively. Finally, at sixth month, the cumulative dose of oral GC in the reduceddose regimen was $<60 \%$ of the standard-dose regimen (table 1).

The RCT by Furuta et $a l^{18}$ was a multicentre trial enrolling 140 patients with newly diagnosed AAV at 34 centres in Japan (with a follow-up of 6 months). This trial evaluated whether a low-dose GC regimen (initial dose at $0.5 \mathrm{mg} / \mathrm{kg} /$ day) is non-inferior to a high-dose regimen (initial dose at $1.0 \mathrm{mg} / \mathrm{kg} /$ day) in efficacy when combined with rituximab for the treatment of AAV. In the low-dose group, prednisolone was discontinued at 5 months, while in the high-dose group, prednisolone was reduced to $10.0 \mathrm{mg} /$ day until 6 months (table 1).

\section{Risk of bias}

Both trials were open-label trials and patients and investigators were aware of the group assignments due to the complexity of the GC regimen. However, the recorded treatment adherence, lack of available cointerventions and objective, easily ascertained nature of the outcomes, the lack of blinding may have introduced minimal bias. Considering the low risk of bias in the other domains, overall risk of bias of both trials was low(online supplemental appendix 3). 


\begin{tabular}{|c|c|c|c|c|c|c|}
\hline $\begin{array}{l}\text { Author } \\
\text { (year) }\end{array}$ & $\begin{array}{l}\text { Name of the study } \\
\text { (Clinicaltrials.gov } \\
\text { number) }\end{array}$ & Country & Study design & $\begin{array}{l}\text { Intervention and comparison } \\
\text { (number of patients) }^{*}\end{array}$ & Patients & Outcomes \\
\hline \multirow[t]{2}{*}{$\begin{array}{l}\text { Walsh et al } \\
(2020)^{24}\end{array}$} & \multirow[t]{2}{*}{$\begin{array}{l}\text { PEXIVAS } \\
\text { (NCT00987389) }\end{array}$} & \multirow[t]{2}{*}{$\begin{array}{l}\text { Multiple } \\
\text { countries }\end{array}$} & \multirow[t]{2}{*}{$\begin{array}{l}\text { Phase III, } \\
\text { randomised, open } \\
\text { label, } 704 \text { patients }\end{array}$} & $\begin{array}{l}\text { Intervention: reduced-dose GC } \\
\text { therapy (initial dose: } 50-75 \mathrm{mg} \text {; } \\
\text { maintenance dose continues } \\
\text { at } 5 \mathrm{mg} / \text { day from the end of } \\
\text { week } 23 \text { until at least week } 52 \text {; } \\
\text { accumulative dose less than } \\
60 \% \text { of the standard) }\end{array}$ & $\begin{array}{l}353 \text { patients } \\
\text { with severe } \\
\text { AAV (mean age } \\
63 \text { years, } 44 \% \\
\text { female) }\end{array}$ & \multirow{2}{*}{$\begin{array}{l}\text { Primary outcome: a } \\
\text { composite of death } \\
\text { from any cause or } \\
\text { ESKD. } \\
\text { Secondary } \\
\text { outcomes: death } \\
\text { from any cause, } \\
\text { ESKD, sustained } \\
\text { remission, serious } \\
\text { adverse events, } \\
\text { serious infections } \\
\text { within } 1 \text { year and } \\
\text { health-related quality } \\
\text { of life. }\end{array}$} \\
\hline & & & & $\begin{array}{l}\text { Comparison: standard-dose GC } \\
\text { therapy (initial dose: } 50-75 \mathrm{mg} \text {; } \\
\text { maintenance dose continues at } \\
5 \mathrm{mg} / \text { day from the end of week } \\
23 \text { until at least week } 52 \text { ) }\end{array}$ & $\begin{array}{l}351 \text { patients } \\
\text { with severe } \\
\text { AAV (mean age } \\
63 \text { years, } 43 \% \\
\text { female) }\end{array}$ & \\
\hline & $\begin{array}{l}\text { LoVAS } \\
\text { (NCT02198248) }\end{array}$ & $\begin{array}{l}\text { Japan, } \\
\text { multicentric }\end{array}$ & $\begin{array}{l}\text { Phase IV, } \\
\text { randomised, open } \\
\text { label, } 140 \text { patients }\end{array}$ & $\begin{array}{l}\text { Comparison : high-dose GC } \\
\text { treatment (initial dose : } 1 \mathrm{mg} / \mathrm{kg} / \\
\text { day; reduced to } 10 \mathrm{mg} / \text { day by } 5 \\
\text { months) }\end{array}$ & $\begin{array}{l}70 \text { patients with } \\
\text { new diagnosis } \\
\text { of AAV (median } \\
\text { age: } 74 ; 37 \% \\
\text { female) }\end{array}$ & $\begin{array}{l}\text { Primary outcome: } \\
\text { remission rate at } 6 \\
\text { months. } \\
\text { Secondary } \\
\text { outcomes: time to } \\
\text { remission, death, } \\
\text { relapse, ESKD and } \\
\text { the first serious } \\
\text { adverse event, } \\
\text { proportion of death, } \\
\text { relapse and ESKD for } \\
\text { efficacy at } 6 \text { months. }\end{array}$ \\
\hline
\end{tabular}

*Although these two trials are comparisons of different doses of GCs, the regimens are different, and the details are in the text. AAV, antineutrophil cytoplasmic antibodies associated vasculitis; ESKD, end-stage kidney disease; GCs, glucocorticoids.

\section{Effect of interventions}

Due to the heterogeneity in the population and in the regimens of GCs between the two trials, we descriptively presented the two trials and did not combine the results using meta-analysis. Since the results of the Walsh's study ${ }^{24}$ showed no interaction between the GC regimen and the plasma exchange, we only focus on the use of GC in conjunction with the purpose of this review.

Online supplemental appendix 4 summarises the GRADE summary of findings for these two trials. Compared with standard-dose regimen, reduced-dose regimen of GC may reduce death (risk difference (RD): from $-1.7 \%$ to $-2.1 \%$, low certainty), while not increasing ESKD (RD: from $-1.5 \%$ to $0.4 \%$, moderate certainty). Results showed that the rate of serious infection at 6 months to 1 year in the reduced-dose regimen tended to be lower than in the standard-dose regimen (RD: from $-12.8 \%$ to $-5.9 \%$, moderate certainty). As one trial showed reduced-dose regimen might increase the risk of serious adverse events (RD: $3.1 \%, 95 \% \mathrm{CI}$ : $-3.7 \%$ to $11.2 \%$ ), while another trial showed reduceddose regimen might reduce the risk (RD: $-18.1 \%$, $95 \%$ CI: $-33 \%$ to $3.2 \%$ ), we are uncertain about the effect of reduced-dose regimen on serious effect (very low certainty). Reduced-dose regimen of GCs probably has trivial or no effect in disease remission, relapse or health-related QoL (Mmoderate to high certainty).

\section{DISCUSSION}

After full-text screening, we identified two studies $^{18} 24$ involving 844 patients who met our selection criteria for studies comparing different dose regimens of GC for the treatment of AAV. According to this systematic review, the results of the absolute effects of low certainty of evidence showed that reduced-dose regimen of GC may reduce death at a follow-up from 6 months to longer than 1 year, while not increasing the rate of ESKD (moderate certainty) among patients with AAV when compared with standard-dose regimen. However, due to the wide CIs, the absolute effects of any intervention on these two outcomes were minimal, and the results were not significantly different. This may be due to the fact that the improvement of the disease by other treatments may mask the benefits of reduced-dose regimens.

In addition, relative to the standard-dose regimen, moderate certainty of evidence indicated that the reduced-dose regimen probably has an important reduction in serious infections at 6 months to 1 year (moderate certainty). This study showed that reduced-dose regimen does have an obvious advantage in reducing infections, which echoes previous studies. ${ }^{172}$ For example, Jayne $e t$ al reported that when high-dose GC was used, infection was most common in the first 6 months of treating severe renal vasculitis. ${ }^{17}$ Therefore, considering that the most common cause of death more than 1 year after diagnosis 
of AAV is infection or uncontrolled vasculitis, ${ }^{16}{ }^{33-35}$ this is particularly important to support the practice of the conclusion of this study.

We are, however, uncertain about the effect of the reduced-dose regimen on other serious adverse events. While Furuta $e t a l$ s trial showed a significant reduction in serious adverse events by reduced-dose regimen, ${ }^{18}$ Walsh $e t$ $a l$ s trial showed the reduced-dose regimen might increase the risk with a wide CI. ${ }^{24}$ In Walsh $e t$ al s trial, although the reduced-dose regimen group had more renal/urinary adverse events than the standard-dose regimen, there was no significant difference in the incidence of ESKD between the two regimen groups as described above. This may be related to the treatment status of the included patients. Among the patients included in the study, the number of patients in the standard-dose regimen who had undergone dialysis before the start of the trial was more than that in the reduced-dose regimen.

The use of GC transformed AAV from an almost uniformly fatal condition to one characterised by remissions and relapses complicated by drug-induced adverse events. Despite the ubiquitous use of GC for AAV, there was no standardisation of dose regimens, guidelines were ambiguous and practice patterns varied substantially. The two trials ${ }^{1824}$ supported the important role GC plays in causing adverse events and highlight the need to optimise their use. Although the two trials found evidence to support one regimen of GC over another, further research is needed to determine whether the GC regimen can be further improved for the treatment of AAV.

The advantages of this systematic review include a comprehensive search of emerging and past evidence across databases without being restricted by study design or publication language, and the use of GRADE approach to assess the quality of evidence. Decisions regarding eligible studies, data extraction and risk of bias assessments were all performed in duplicate, and calibration exercises were conducted before the formal start of the project. By excluding non-RCT studies, we limited the risk of bias. The RCTs we included are of sound methodological quality. AAV is a rare disease, and the PEXIVAS trial is the largest global trial on the subject so far which has improved the generalisability of the results through the efforts of national and international vasculitis networks and extensive selection criteria.

The results of our systematic review also have some limitations. First, only two trials were included and although they were broadly inclusive and contained more events than any other trial in this disease, the total statistical information remains low. This is particularly obvious for serious adverse events other than serious infection. However, the reduced-dose GC regimen should not result in more treatment-related adverse events (ie, it is illogical that a lower exposure to GC would have anything but the same or lower rate of GC caused side effects) and there is reasonable precision around the efficacy outcomes. This limitation is expected to result in an underappreciation of the benefits of reducing the GC dose, a limitation that is supported by observational studies of GC which suggests reducing GC exposure may also reduce fractures, peptic ulcer disease, psychiatric disease, weight gain and dysglycaemia. In addition, despite the excellent methodological quality of the included trial, this is an open label and is subject to biases despite our relative confidence that differential treatment or outcome ascertainment was at low risk. Despite the large scale of this study for a rare disease, the degree to which the results can be generalised to patients with non-severe AAV is uncertain, although it is likely safer to extrapolate the safety of the regimen from more severe illness to less severe illness rather than less severe to more severe.

\section{CONCLUSION}

An important general rule is that in routine clinical practice, the use of conventional GC should be 'as much as necessary, but as little as possible'. ${ }^{36}$ Therefore, compared with the standard-dose regimen, the reduced-dose regimen of GC may reduce death, probably has little or no effect on ESKD among patients with AAV, and resulted in a lower risk of serious infections at 6 months to 1 year. Future clinical trials should evaluate whether GC dosing can be further safely reduced.

\section{Author affiliations}

${ }^{1}$ Department of Health Research Methods, Evidence and Impact, McMaster University, Hamilton, Ontario, Canada

${ }^{2}$ West China School of Nursing/Department of Nursing, West China Hospital, Sichuan University, Chengdu, Sichuan, China

${ }^{3}$ Department of Medicine, McMaster University, Hamilton, Ontario, Canada ${ }^{4}$ Pharmacy Department/Evidence-Based Pharmacy Center, West China Second University Hospital, Sichuan University, Chengdu, Sichuan, China

${ }^{5}$ Department of Medicine, University of Cambridge, Cambridge, UK

${ }^{6}$ Division of Rheumatology, Department of Medicine and Division of Clinical Epidemiology, Department of Biostatistics, Epidemiology and Informatics, University of Pennsylvania, Philadelphia, Pennsylvania, USA

${ }^{7}$ Schulich School of Medicine and Dentistry, Western University, London, Ontario, Canada

${ }^{8}$ Michael G. DeGroote School of Medicine, McMaster University, Hamilton, Ontario, Canada

${ }^{9}$ DeGroote Institute for Pain Research and Care, McMaster University, Hamilton, Ontario, Canada

${ }^{10} \mathrm{Clinic}$ for Rheumatology, Kantonsspital St Gallen, St Gallen, Switzerland ${ }^{11}$ Population Health Research Institute, Hamilton Health Sciences / McMaster University, Hamilton, Ontario, Canada

Twitter Muhammad Muneeb Ahmed @muneebahmed1a and Michael Walsh @ lastwalsh

Acknowledgements We thank members of the Rapid Recommendations panel for critical feedback on outcome and subgroup selection, GRADE judgments and manuscript feedback.

Contributors MW, AM, DJ, PAM and GG conceived the study idea. RJC performed the literature search. YX, JED, TAB and MMA performed the screening, data abstraction and risk of bias assessments. YX, LZ and MW performed the data analysis. YX, GG, LZ, RS, DJ, PAM and MW interpreted the data. YX, GG and LZ performed the certainty assessment. YX, GG, LZ and MW drafted the manuscript. All authors critically revised the manuscript. All authors approved the final version of the manuscript. YX and MW had full access to the data in the study and takes responsibility for the integrity of the data and the accuracy of the data analysis. YX and MW are the guarantors.

Funding This work was supported by China Scholarship Council grant number 201906240082. 
Competing interests None declared.

Patient consent for publication Not applicable.

Ethics approval This study does not involve human participants.

Provenance and peer review Not commissioned; externally peer reviewed.

Data availability statement № data are available.

Supplemental material This content has been supplied by the author(s). It has not been vetted by BMJ Publishing Group Limited (BMJ) and may not have been peer-reviewed. Any opinions or recommendations discussed are solely those of the author(s) and are not endorsed by BMJ. BMJ disclaims all liability and responsibility arising from any reliance placed on the content. Where the content includes any translated material, BMJ does not warrant the accuracy and reliability of the translations (including but not limited to local regulations, clinical guidelines, terminology, drug names and drug dosages), and is not responsible for any error and/or omissions arising from translation and adaptation or otherwise.

Open access This is an open access article distributed in accordance with the Creative Commons Attribution Non Commercial (CC BY-NC 4.0) license, which permits others to distribute, remix, adapt, build upon this work non-commercially, and license their derivative works on different terms, provided the original work is properly cited, appropriate credit is given, any changes made indicated, and the use is non-commercial. See: http://creativecommons.org/licenses/by-nc/4.0/.

\section{ORCID iDs}

Yingqi Xiao http://orcid.org/0000-0001-8766-5184

Linan Zeng http://orcid.org/0000-0001-9892-2000

Reed AC Siemieniuk http://orcid.org/0000-0002-3725-3031

Muhammad Muneeb Ahmed http://orcid.org/0000-0003-4208-6247

Michael Walsh http://orcid.org/0000-0001-8292-2014

\section{REFERENCES}

1 Houben E, Penne EL, Voskuyl AE, et al. Cardiovascular events in anti-neutrophil cytoplasmic antibody-associated vasculitis: a metaanalysis of observational studies. Rheumatology 2018;57:555-62.

2 Bosch X, Guilabert A, Font J. Antineutrophil cytoplasmic antibodies. Lancet 2006;368:404-18.

3 Wallace ZS, Miloslavsky EM. Management of ANCA associated vasculitis. BMJ 2020;368:m421.

4 Jennette JC, Falk RJ. Pathogenesis of antineutrophil cytoplasmic autoantibody-mediated disease. Nat Rev Rheumatol 2014;10:463-73.

5 Salvador F. ANCA associated vasculitis. Eur J Intern Med 2020;74:18-28.

6 Smith RM. Update on the treatment of ANCA associated vasculitis. Presse Med 2015;44:e241-9.

7 Hoffman GS, Kerr GS, Leavitt RY, et al. Wegener granulomatosis: an analysis of 158 patients. Ann Intern Med 1992;116:488-98.

8 Walsh M, Merkel PA, Peh CA, et al. Plasma exchange and glucocorticoid dosing in the treatment of anti-neutrophil cytoplasm antibody associated vasculitis (PEXIVAS): protocol for a randomized controlled trial. Trials 2013;14:73

9 Keller SF, Miloslavsky EM. Corticosteroids in antineutrophil cytoplasmic antibody-associated vasculitis. Rheum Dis Clin North Am 2016;42:91-101.

10 Booth AD, Almond MK, Burns A, et al. Outcome of ANCA-associated renal vasculitis: a 5-year retrospective study. Am J Kidney Dis 2003;41:776-84.

11 Jennette JC, Falk RJ. Small-vessel vasculitis. N Engl J Med 1997;337:1512-23.

12 Lally L, Spiera R. Current landscape of antineutrophil cytoplasmic antibody-associated vasculitis: classification, diagnosis, and treatment. Rheum Dis Clin North Am 2015;41:1-19. vii.

13 Stahn C, Buttgereit F. Genomic and nongenomic effects of glucocorticoids. Nat Clin Pract Rheumatol 2008;4:525-33.
14 Walton EW. Giant-cell granuloma of the respiratory tract (Wegener's granulomatosis). Br Med J 1958;2:265-70.

15 de Groot K, Harper L, Jayne DRW, et al. Pulse versus daily ora cyclophosphamide for induction of remission in antineutrophil cytoplasmic antibody-associated vasculitis: a randomized trial. Ann Intern Med 2009;150:670-80.

16 De Groot K, Rasmussen N, Bacon PA, et al. Randomized trial of cyclophosphamide versus methotrexate for induction of remission in early systemic antineutrophil cytoplasmic antibody-associated vasculitis. Arthritis Rheum 2005;52:2461-9.

17 Jayne DRW, Gaskin G, Rasmussen N, et al. Randomized trial of plasma exchange or high-dosage methylprednisolone as adjunctive therapy for severe renal vasculitis. J Am Soc Nephrol 2007;18:2180-8.

18 Furuta S, Nakagomi D, Kobayashi Y, et al. Effect of Reduced-Dose vs high-dose glucocorticoids added to rituximab on remission induction in ANCA-associated vasculitis: a randomized clinical trial. JAMA 2021;325:2178-87.

19 Keller SF, Miloslavsky EM. Corticosteroids in antineutrophil cytoplasmic antibody-associated vasculitis. Rheum Dis Clin North Am 2016;42:91-101.

20 Flossmann O, Berden A, de Groot K, et al. Long-term patient survival in ANCA-associated vasculitis. Ann Rheum Dis 2011;70:488-94.

21 Furuta S, Chaudhry AN, Hamano Y, et al. Comparison of phenotype and outcome in microscopic polyangiitis between Europe and Japan. J Rheumatol 2014;41:325-33.

22 Walsh M, Merkel PA, Mahr A, et al. Effects of duration of glucocorticoid therapy on relapse rate in antineutrophil cytoplasmic antibody-associated vasculitis: a meta-analysis. Arthritis Care Res 2010;62:1166-73.

23 Wada T, Hara A, Arimura Y, et al. Risk factors associated with relapse in Japanese patients with microscopic polyangiitis. J Rheumatol 2012;39:545-51.

24 Walsh M, Merkel PA, Peh C-A, et al. Plasma exchange and glucocorticoids in severe ANCA-associated vasculitis. N Engl J Med 2020;382:622-31.

25 Moher D, Liberati A, Tetzlaff J, et al. Preferred reporting items for systematic reviews and meta-analyses: the PRISMA statement. $J$ Clin Epidemiol 2009;62:1006-12.

26 Salvador F. ANCA associated vasculitis. Eur J Intern Med 2020;74:18-28.

27 Pagnoux C. Updates in ANCA-associated vasculitis. Eur J Rheumatol 2016;3:122-33.

28 Guyatt G, Busse JW. Risk of bias in randomized trials. GROWTH evidence, 2016. Available: https://growthevidence.com/gordonh-guyatt-md-msc-and-jason-w-busse-dc-phd [Accessed $6 \mathrm{Apr}$ 2020]

29 Guyatt G, Oxman AD, Akl EA, et al. GRADE guidelines: 1. Introduction-GRADE evidence profiles and summary of findings tables. J Clin Epidemiol 2011;64:383-94.

30 Guyatt GH, Oxman AD, Santesso N, et al. GRADE guidelines: 12 Preparing summary of findings tables-binary outcomes. J Clin Epidemiol 2013;66:158-72.

31 Guyatt $\mathrm{GH}$, Thorlund K, Oxman AD, et al. GRADE guidelines: 13. Preparing summary of findings tables and evidence profilescontinuous outcomes. J Clin Epidemiol 2013;66:173-83.

32 Illei GG, Yarboro CH, Kuroiwa T, et al. Long-term effects of combination treatment with fludarabine and low-dose pulse cyclophosphamide in patients with lupus nephritis. Rheumatology 2007;46:952-6.

33 Flossmann O, Berden A, de Groot K, et al. Long-term patient surviva in ANCA-associated vasculitis. Ann Rheum Dis 2011;70:488-94.

34 Jones RB, Tervaert JWC, Hauser T, et al. Rituximab versus cyclophosphamide in ANCA-associated renal vasculitis. $N$ Engl $J$ Med 2010;363:211-20.

35 Jayne D, Rasmussen N, Andrassy K, et al. A randomized trial of maintenance therapy for vasculitis associated with antineutrophil cytoplasmic autoantibodies. N Engl J Med 2003;349:36-44.

36 Buttgereit F, Burmester G-R, Lipworth BJ. Optimised glucocorticoid therapy: the sharpening of an old spear. Lancet 2005;365:801-3. 